\title{
Scimitar syndrome in infancy Role of embolisation of systemic arterial supply to right lung
}

\author{
D F DICKINSON, R W GALLOWAY, R MASSEY, R SANKEY, R ARNOLD \\ From the Regional Paediatric Cardiothoracic Unit, Royal Liverpool Children's Hospital, Myrtle Street, Liverpool
}

SUMMARY Four infants with scimitar syndrome are described. All had a systemic arterial supply to part of the right lung and one was treated successfully by embolisation of this vessel. The role of the systemic arterial supply to the right lung in producing symptoms in infants with scimitar syndrome is discussed.

The scimitar syndrome ${ }^{1}$ is a well recognised radiological entity in which anomalous drainage of one or more of the right pulmonary veins to the inferior vena cava produces a characteristic shadow at the right cardiac border. The syndrome is variable in its expression and though the majority of reported cases have been older children or adults ${ }^{23}$ with only minimal symptoms, occasional cases have been described in whom intractable symptoms developed early in infancy. Some degree of hypoplasia of the right lung with rotation of the heart into the right hemithorax is common and in many cases the right lung receives an aberrant arterial supply from a systemic artery. Additional intracardiac malformations are well recognised but relatively uncommon.

We have recently seen four infants who developed severe symptoms within the first weeks of life. All had an arterial supply to the right lung from a systemic artery and one was treated successfully by selective embolisation of this artery.

\section{Case reports}

\section{CASE 1}

This patient presented at 3 days of age with dyspnoea. The cardiac impulse was predominantly to the right of the sternum and a soft systolic murmur was audible. The chest $x$-ray film showed dextrocardia and cardiac enlargement, and the electrocardiogram showed an $\mathrm{rS}$ pattern across the precordium. Cardiac catheterisation was performed at 8 days of age because of increasing cardiac failure and the haemodynamic findings are summarised in the Table. Bronchoscopy and bronchography at 6 months of age showed only two major bronchi in the right lung, supplying the upper and middle lobes. The trachea and left bronAccepted for publication 14 January 1982
Table Cardiac catheterisation data in four patients

\begin{tabular}{|c|c|c|c|c|}
\hline \multirow[t]{2}{*}{ Case No. } & \multirow{2}{*}{$\begin{array}{l}\text { Age at } \\
\text { catheter } \\
\text { (days) }\end{array}$} & \multicolumn{2}{|c|}{ Pressure $(\mathrm{mmHg})$} & \multirow[t]{2}{*}{$Q p / Q s$} \\
\hline & & $M P A$ & Systemic & \\
\hline $\begin{array}{l}1 \\
1 \\
2 \\
3 \\
3 \\
4 \\
4\end{array}$ & $\begin{array}{r}8 \\
194 \\
13 \\
45 \\
56 \\
4 \\
23\end{array}$ & $\begin{array}{l}50 \\
65 \\
85 \\
40 \\
55 \\
80 \\
75\end{array}$ & $\begin{array}{r}64 \\
70 \\
90 \\
105 \\
100 \\
80 \\
78\end{array}$ & $\begin{array}{l}3.5 \\
2.0 \\
2.2 \\
3.0 \\
2.0 \\
3.0\end{array}$ \\
\hline
\end{tabular}

chus were normal. In spite of vigorous treatment of $\underset{\vec{P}}{\rightrightarrows}$ congestive cardiac failure and respiratory infections the condition of the infant deteriorated and a second cardiac catheterisation was perfomed at 7 months. Angiography showed the heart to be displaced to the right with enlargement of the right atrium. The right pulmonary artery gave branches only to the upper and middle lobes while the lower lobe was supplied from a large vessel arising from the coeliac axis. Below the origin of this artery the aorta abruptly narrowed in calibre (Fig. 1) but no pressure gradient was recorded. An atrial septal defect was present and all the right pulmonary veins drained to the inferior vena $\frac{D}{O}$ cava. Open heart surgery was performed to close the atrial septal defect (sinus venosus type) but immedi- N ately after operation it was apparent that there was a considerable shunt through the sequestered right lower lobe. A pneumonectomy was performed $24 \mathrm{\omega}$ hours later but the patient died within hours. Necropsy confirmed the known anatomical findings.

CASE 2

This patient was first seen at 9 days of age with dyspnoea and a systolic murmur. The chest $x$-ray film $\frac{D}{\mathbb{D}}$ showed mesocardia, cardiac enlargement, and pul- $\stackrel{\odot}{\stackrel{\odot}{\odot}}$ monary plethora. The electrocardiogram showed an $\triangle$ rS pattern across the left precordium. Cardiac 


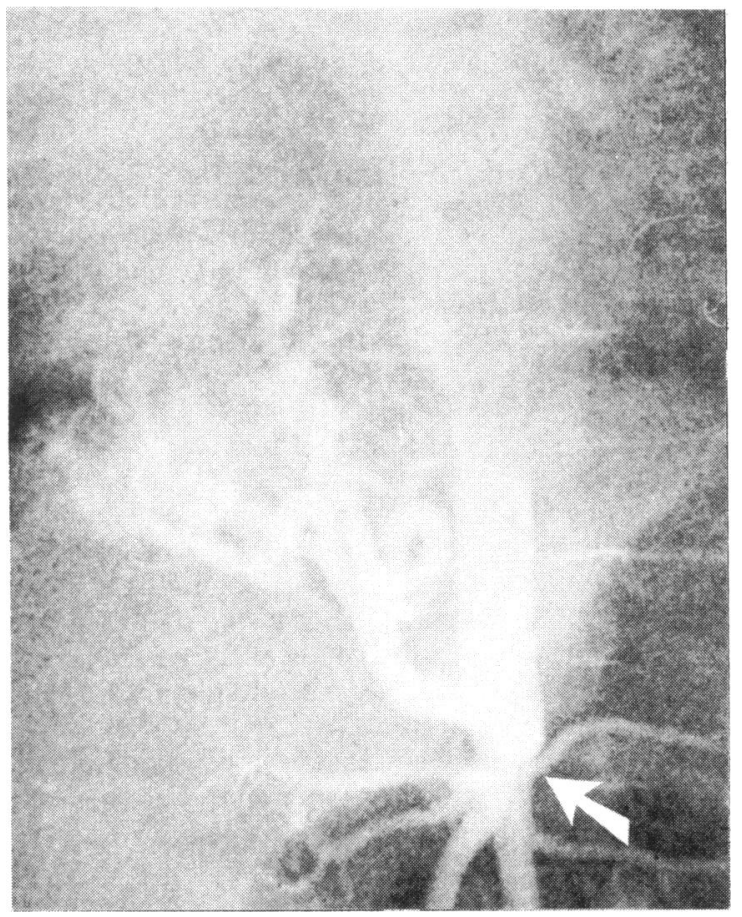

Fig. 1 Aortogram in case 1 . A large artery arises from the coeliac axis to supply the right lower lobe. At the point of origin of this artery (arrow) the aorta narrows abruptly. catheterisation at 13 days confirmed the presence of the scimitar syndrome with drainage of all the right pulmonary veins to the inferior vena cava. The branching pattern of the right pulmonary artery was abnormal with only two main divisions, but the lower zone of the lung received an additional arterial supply from a large vessel which arose from the coeliac axis. At this point there was an abrupt change in calibre of the descending aorta. Because of increasing cardiac failure an attempt was made, at 16 days, to eliminate flow through this aberrant vessel by embolisation using a catheter introduced through the femoral artery. Unfortunately the aberrant artery could not be entered and the procedure was abandoned. Two months later, after a period of cardiac failure and respiratory infections requiring assisted ventilation, a right pneumonectomy was performed, but the infant died in the immediate postoperative period. Necropsy confirmed the known findings and histological examination of the lungs showed intense muscularisation of pulmonary arteries and arterioles, not only in the right lower zone but also in the left lung. The right lung was moderately hypoplastic and had no visible fissures.

\section{CASE 3}

This patient had Hirschsprung's disease. An ileostomy was performed in the first week of life and the patient was admitted to the cardiac unit at 6 weeks of age with
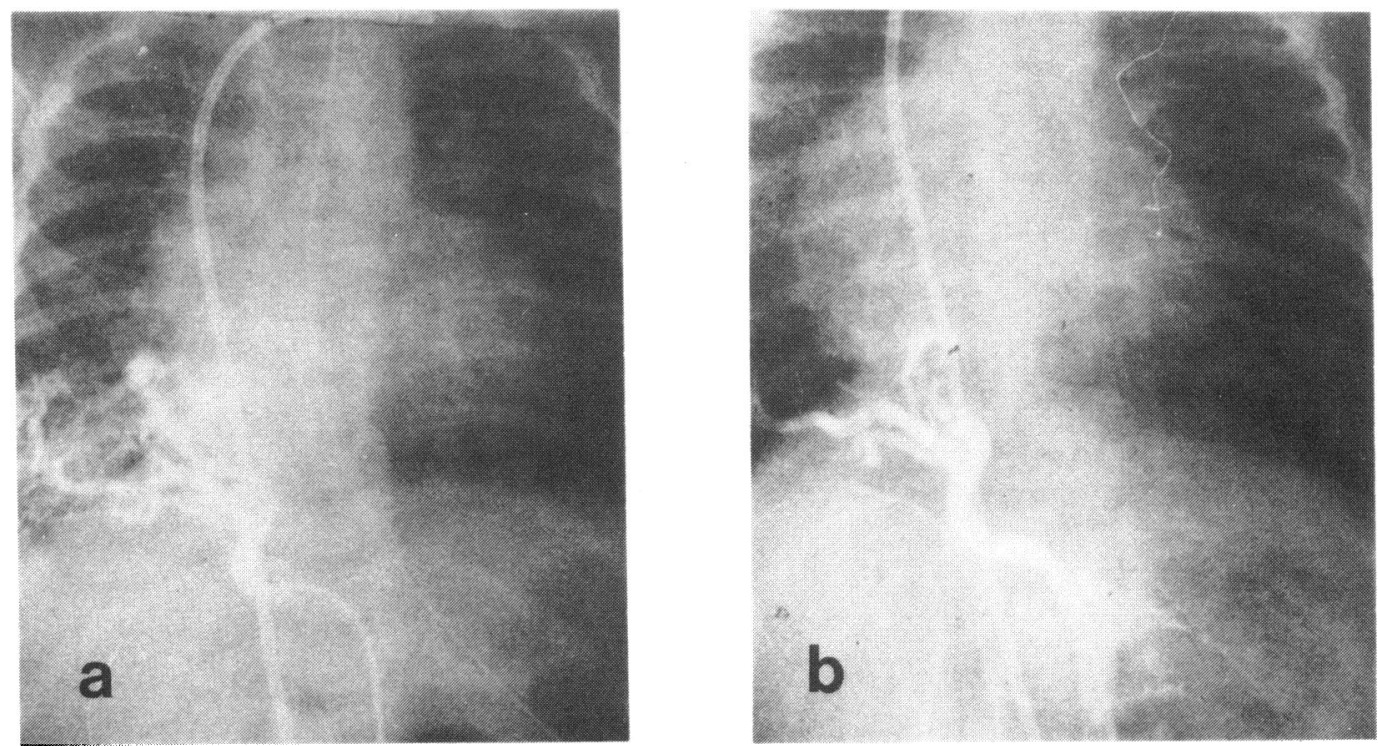

Fig. 2 Selective angiogram in the aberrant artery in case $3(a)$ before and (b) after embolisation. After embolisation though the proximal part of the artery is patent there is no capillary phase and no filling of the inferior vena cava or right atrium. 
dyspnoea. A soft systolic murmur was present and the chest $x$-ray film showed laevocardia, with cardiomegaly and pulmonary plethora. The electrocardiogram showed evidence of right atrial and right ventricular hypertrophy. Cardiac catheterisation was performed soon after admission. Angiography showed the heart to be displaced slightly to the right with considerable dilatation of the right atrium. The right pulmonary artery had a normal branching pattern and the right pulmonary veins drained into the inferior vena cava. The left upper lobe pulmonary vein entered the innominate vein. A large vessel from the coeliac axis penetrated the diaphragm to give a second arterial supply to the right lower lobe. The aorta tapered abruptly below the origin of this artery. During the following two weeks, increasing cardiac failure and respiratory difficulties developed. At 56 days,
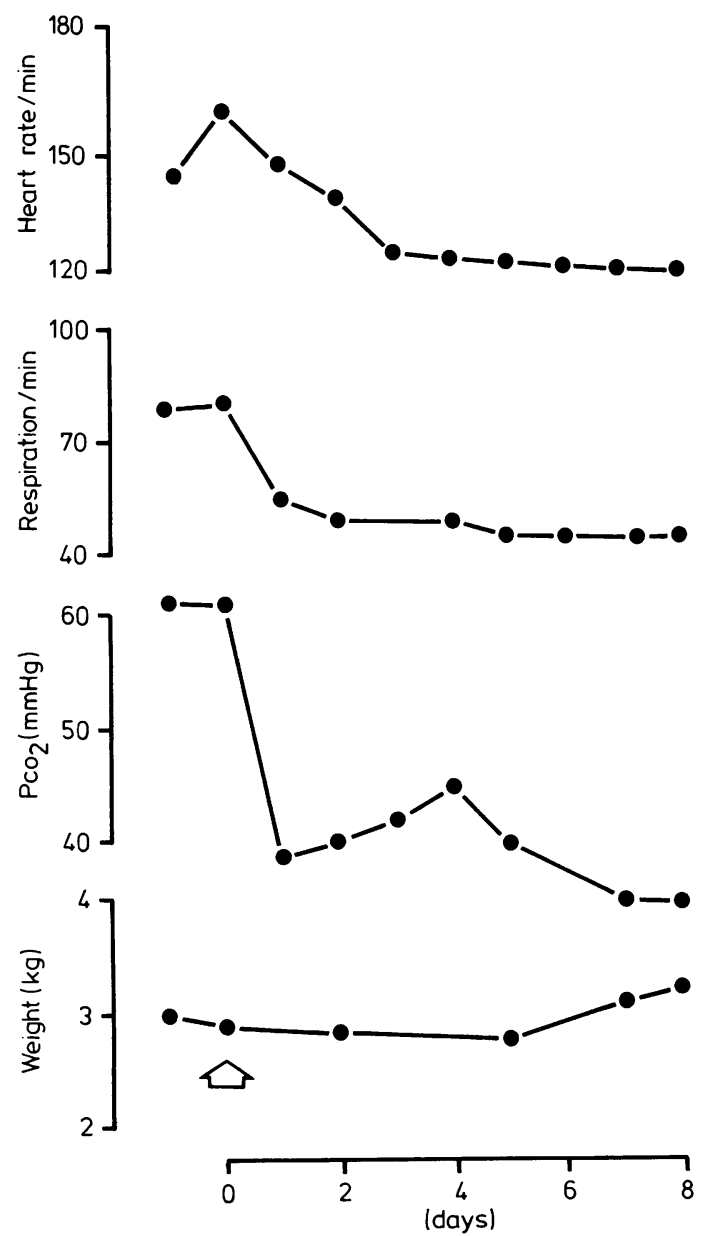

Fig. 3 Heart rate, respiratory rate, $\mathrm{PCO}_{2}$, and weight of case 3 before and after embolisation of aberrant artery. The arrow indicates the date of embolisation. when the infant weighed $2.9 \mathrm{~kg}$ a $4 \mathrm{FG}$ catheter with end and side holes was introduced from the femoral artery and manipulated into the aberrant artery. The catheter position was verified by selective angiography and 2 to $3 \mathrm{~mm}$ Gelfoam fragments were injected through the catheter until the artery was obstructed (Fig. 2) After this procedure there was a rapid improvement in the infant's condition (Fig. 3) and she was discharged from hospital three weeks later. Progress was satisfactory at 7 months of age.

\section{CASE 4}

This infant presented on the first day of life with cyanosis and was found to have dextrocardia on the chest $x$-ray film. Close inspection of the film disclosed an opacity behind the heart compatible with a scimitar shadow, and cardiac catheterisation at 4 days of age confirmed this diagnosis. Though the right lung was very hypoplastic, the branching of the right pulmonary artery was normal. All the right pulmonary veins entered the inferior vena cava. An aberrant vessel from the region of the renal arteries gave a second arterial supply to the right lower lobe. The baby subsequently developed severe cardiac failure with dis- $N$ turbance of serum electrolyte concentrations secondary to diuretic therapy. Embolisation of the aberrant artery was performed at 23 days using a $3 F G$ catheter introduced percutaneously from the femoral artery and Gelfoam fragments soaked in $50 \%$ dextrose. The baby was critically ill at the beginning of the procedure and though the artery was successfully occluded she remained in low cardiac output, developed renal failure, and died four days later. The renal arteries were shown to be patent on an aortogram after embolisation. Consent for necropsy was refused.

\section{Discussion}

The majority of reported cases of the scimitar syndrome have been older children or adults in whom symptoms have been minimal or absent. ${ }^{23}$ The good prognosis for most of these patients is in pronounced contrast to the outlook for those patients who develop symptoms early in infancy. The initial descriptions by Chassinat $^{4}$ and Cooper ${ }^{5}$ in 1836 , were followed by a number of accounts which described individual $\tilde{N}$ infants who died within the first year, though in many $\underset{\omega}{\mathrm{N}}$ cases the nature of the cardiac defect was not recognised during life.$^{6-11}$ The patient of Chassinat ${ }^{4}$ prob- $c$ ably died as a result of coexisting pulmonary atresia, $\mathbb{D}$ but the remaining patients did not have major cardiac $\stackrel{?}{?}$ defects which might have accounted for their death. 0 Neill et al. ${ }^{1}$ reported the case of an infant who developed symptoms at 7 months of age but who survived until a pneumonectomy was performed at $2 \frac{1}{2} \stackrel{\mathbb{D}}{\triangle}$ years. 
A number of factors may influence the development of symptoms in the scimitar syndrome. The normal right lung carries approximately $55 \%$ of the pulmonary blood flow. ${ }^{12}$ In the absence of any additional site of shunting, anomalous drainage of all the right pulmonary veins to the systemic veins might therefore be expected to result in a left to right shunt with a pulmonary to systemic flow ratio of about $2: 1$. A shunt of this size would be unlikely to produce symptoms in infancy and would probably be well tolerated even in the longer term. Extreme hypoplasia of the right lung may limit the size of the shunt to such an extent that no detectable rise in oxygen saturation may be recorded in the great veins or right heart, as in the cases reported by Kiely et al. ${ }^{2}$ Conversely, an arterial supply to the right lung from the descending aorta may function as a large arteriovenous fistula and our experience suggests that it is the size of the shunt through these vessels which determines the presence and severity of symptoms in infancy. The abrupt change in calibre of the descending aorta distal to the origin of the aberrant vessel previously noted by Mortensson and Lundstrom ${ }^{10}$ is perhaps an indication of the significance of the shunt in these subjects. Kiely et al., ${ }^{2}$ in a review of 67 reported cases, commented on the variability in size of these vessels and in many older asymptomatic patients they may be absent.

To our knowledge, successful treatment of a severely symptomatic infant with scimitar syndrome has not previously been reported. The infant described by Woody et al.,$^{13}$ however, deserves mention because of the similarities to the present cases. This patient ${ }^{13}$ had hypoplasia of the right lung, a systemic arterial supply to the right lower lobe from the descending aorta, and coarctation of the aorta, but the right pulmonary veins drained via an azygos vein to the superior vena cava. At 1 month of age the aberrant arteries were ligated through a right thoracotomy and the azygos vein was anastomosed to the left atrium, with a dramatic fall in pulmonary artery pressure. Pneumonectomy became necessary within 24 hours of operation because of thrombosis of the azygos vein. Mortensson and Lundstrom ${ }^{10}$ reported the case of a baby with the scimitar syndrome who developed symptoms at 9 days of age and subsequently underwent a pneumonectomy but who died at 1 year. In this patient the right pulmonary artery was absent. In many patients with the scimitar syndrome, including three of our own patients, parts of the right lung have a dual arterial supply from both the pulmonary artery and the descending aorta. It therefore seems appropriate to consider therapeutic measures which would conserve functioning lung where possible. Open heart surgery to divert the anomalous venous channel into the left atrium has been accomplished in older patients ${ }^{14}{ }^{15}$ but is unlikely to be successful in infants unless the shunt through the aberrant artery is also abolished. This may present considerable difficulty if pneumonectomy is to be avoided since the vessels tend to divide into many branches above the diaphragm.

Therapeutic obliteration of selected arteries by embolisation through a catheter has been used recently in a variety of situations. ${ }^{16} 17$ Using this technique we were able to block the aberrant arterial supply to the right lung in two of the three patients in whom it was attempted, with a dramatic improvement in the condition of one patient. In the patient who died after embolisation the outcome was probably related to the poor condition of the patient at the start of the procedure, and a favourable result might have been achieved if intervention had been earlier. The rapid deterioration of this patient and the early changes of pulmonary vascular disease in both lungs of case 2 emphasise the need for urgent treatment in these cases. A similar pattern of pulmonary vascular change to our patient was seen in the patient reported by Neill et al. ${ }^{1}$

As yet there is insufficient information on which to base an accurate assessment of the risk of embolisation procedures in small babies, but evidence from large series of older patients suggests that the risk is acceptable. ${ }^{1617}$ In infants with the scimitar syndrome and an aberrant arterial supply to the right lung, the alternatives appear to be a thoracotomy to ligate the leash of vessels passing through the diaphragm, or an abdominal approach to ligate the vessel close to its origin. Both procedures may present considerable difficulties with the chance of only partial success. On the basis of our recent experience we believe that embolisation of the aberrant arterial supply may prove to be an effective palliative measure, permitting postponement of open heart surgery to connect the anomalous pulmonary veins to the left atrium until later in childhood.

\section{References}

1 Neill CA, Ferencz C, Sabiston DC, Sheldon H. The familial occurrence of hypoplastic right lung with systemic arterial supply and venous drainage "scimitar syndrome". Bulletin of the Fohns Hopkins Hospital 1960; 107: $1-21$.

2 Kiely B, Filler J, Stone S, Doyle EF. Syndrome of anomalous venous drainage of the right lung to the inferior vena cava. A review of 67 reported cases and three new cases in children. Am $\mathcal{F}$ Cardiol 1967; 20: 102-16.

3 Jue KL, Amplatz K, Adams $\mathbf{P ~ J r}$, Anderson RC. Anomalies of great vessels associated with lung hypoplasia. The scimitar syndrome. Am f Dis Child 1966; 111: $35-44$. 
4 Chassinat $R$. Observation d'anomalies anatomiques remarquables de l'appareil circulatoire avec hépatocèle congénitale, n'ayant donné lieu pendant la vie à aucun symptôme particulier. Archives Generales de Medicine 1836; 11: 80-91.

5 Cooper G. Case of malformation of the thoracic viscera: consisting of imperfect development of right lung, and transposition of the heart. London Medical Gazette 1836; 18: 600-2.

6 Park EA. Defective development of the right lung due to anomalous development of the right pulmonary artery and vein, accompanied by dislocation of the heart simulating dextrocardia. Proceedings of the New York Pathological Society 1912; 12: 88-93.

7 Halasz NA, Halloran KH, Liebow AA. Bronchial and arterial anomalies with drainage of the right lung into the inferior vena cava. Circulation 1956; 14: 826-46.

8 Van Praagh R, Van Praagh S, Vlad P, Keith JD. Anatomic types of congenital dextrocardia. Diagnostic and embryonic implications. Am $\mathcal{F}$ Cardiol 1964; 13: 510-31.

9 Farnsworth AE, Ankeney JL. The spectrum of the scimitar syndrome. $\mathcal{F}$ Thorac Cardiovasc Surg 1974; 68: 3742.

10 Mortensson W, Lundstrom NR. Broncho-pulmonary vascular malformation syndrome causing left heart failure during infancy. Acta Radiol [Diagn] (Stockh) 1971; 11: 449-58.

11 Kuiper-Oosterwal $\mathrm{CH}$, Moulaert A. The scimitar syndrome in infancy and childhood. Eur $\mathcal{F}$ Cardiol 1973; 1: 55-61.
12 Bryan AC, Bentivoglio LG, Beerel F, Macleish $H$, Zidulka A, Bates DV. Factors affecting regional distribution of ventilation and perfusion in the lung. $\mathcal{F} A p p l$ Physiol 1964; 19: 395-402.

13 Woody JN, Graham TP Jr, Bradford WD, Sabiston DC Jr, Canent RV Jr. Hypoplastic right lung with systemic blood supply and anomalous pulmonary venous drainage: reversal of pulmonary hypertension with surgical management in infancy. Am Heart $\mathcal{F}$ 1972; 83: 82-8.

14 Frye RL, Krebs M, Rahimtoola SH, Ongley PA, Hallermann FJ, Wallace RB. Partial anomalous pulmonary venous connection without atrial septal defect. Am $\mathcal{F}$ Cardiol 1968; 22: 242-50.

15 Murphy JW, Kerr AR, Kirklin JW. Intracardiac repair for anomalous pulmonary venous connection of right lung to inferior vena cava. Ann Thorac Surg 1971; 11: $38-45$.

16 Berenstein A, Kricheff II. Catheter and material selection for transarterial embolization: technical considerations. Radiology 1979; 132: 619-30.

17 Kaufman SL, Kumar AAJ, Roland J-MA, et al. Transcatheter embolization in the management of congenital arteriovenous malformations. Radiology 1980; 137: 21-9.

Requests for reprints to Dr D F Dickinson, Royal Liverpool Children's Hospital, Myrtle Street, Liverpool L7 7DG. 